\title{
Miscibility Development Computation in Enhanced Oil Recovery by Flare Gas Flooding
}

\author{
Tjokorde Walmiki Samadhi ${ }^{1}$, Utjok W.R. Siagian ${ }^{2} \&$ Angga P. Budiono ${ }^{1}$ \\ ${ }^{1}$ Chemical Engineering Program at Institut Teknologi Bandung, Jalan Ganesha 10 \\ Bandung, Jawa Barat 40132, Indonesia, Phone: 62222500989, Fax: 62222501438 \\ ${ }^{2}$ Petroleum Engineering Program at InstitutTeknologi Bandung, Jalan Ganesha 10 \\ Bandung, Jawa Barat 40132, Indonesia, Phone: 62222504955, Fax: 62222511155 \\ E-mail: twsamadhi@che.itb.ac.id
}

\begin{abstract}
The use of flare gas as injection gas in miscible gas flooding enhanced oil recovery (MGF-EOR) presents a potential synergy between oil production improvement and greenhouse gases emission mitigation. This work is a preliminary evaluation of the feasibility of miscible flare gas injection based on phase behavior computations of a model oil $\left(43 \% \mathrm{n}-\mathrm{C}_{5} \mathrm{H}_{12}: 57 \% \mathrm{n}-\mathrm{C}_{16} \mathrm{H}_{34}\right)$ and a model flare gas $\left(91 \% \mathrm{CH}_{4}: 9 \% \mathrm{C}_{2} \mathrm{H}_{6}\right)$. The computations employed the multiple mixing-cell model with Peng-Robinson and PC-SAFT equations of state, and compared the minimum miscibility pressure (MMP) value in the cases of flare gas injection and $\mathrm{CO}_{2}$ injection. For $\mathrm{CO}_{2}$ injection, both equations of state produced MMP values close to the measured value of $10.55 \mathrm{MPa}$. Flare gas injection MMP values were predicted to be 3.6-4.5 times those of $\mathrm{CO}_{2}$ injection. This very high MMP implies high gas compression costs, and may compromise the integrity of the reservoir. Subsequent studies shall explore the gas-oil miscibility behavior of mixtures of flare gas with intermediate hydrocarbon gases and $\mathrm{CO}_{2}$, in order to identify a suitable approach for rendering flare gas feasible as an injection gas in MGF-EOR.
\end{abstract}

Keywords: miscible gas flooding; MMP; PC-SAFT; multiple mixing cell; EOR.

\section{$1 \quad$ Introduction}

Gas flaring refers to the disposal of light to intermediate molecular weight streams in process plants by incineration, and the subsequent release of the combustion gases to the atmosphere. Gas flaring by the oil and gas production sector is a major contributor to the greenhouse gases (GHG) emissions in Indonesia. In 2002, GHG emission generated by gas flaring in Indonesia was equivalent to approximately $72 \%$ of the total emission of the Asia-Oceania region, or approximately 5.6\% of the global GHG emission [1]. In 2004, the total volumetric flow rate of gas flaring in Indonesia reached 358.3 MMSCFD, which was generated by 506 oil and gas production fields. This emission rate is equivalent to $4.3 \%$ of Indonesia's total natural gas production rate [2].

Received December $30^{\text {th }}, 2011$, Revised May $9^{\text {th }}, 2012$, Accepted for publication July, $19^{\text {th }}, 2012$.

Copyright (C) 2012 Published by LPPM ITB \& PII, ISSN: 1978-3051, DOI: 10.5614/itbj.eng.sci.2012.44.3.5 
An alternative application that could conceivably be engaged to reduce gas flaring from the oil and gas sector involves using the gas as an injection gas in the miscible gas flooding enhanced oil recovery (MGF-EOR) process. The MGF-EOR process basically involves the injection of light gases into the oil reservoir near or at the minimum miscibility pressure (MMP), which is defined as the threshold reservoir pressure at which a complete miscibility between gas and oil occurs throughout the vapor-liquid interfacial contact zone (also known as the multiple-contact miscibility phenomenon). The miscibility of the injection gas in the oil dramatically decreases the viscosity of the oil, with a concurrent increase of its fluidity. If proven to be techno-economically feasible, the use of flare gas as injection gas in the MGF-EOR represents a significant advancement in the synergy between greenhouse gases management and oil production improvement efforts.

The MMP is obviously a key engineering parameter in the design of an MGFEOR process. Unfortunately, the prediction of the MMP of an oil reservoir is not always trivial due to the dependence of this thermodynamic property on the composition of the trapped oil and on the reservoir temperature. These are properties that are not always known with sufficient accuracy. Laboratory estimation of MMP is traditionally done by using the slim tube apparatus, in which the injection gas are brought into contact with the oil inside a long, coiled tube packed with sand or fine glass beads. The profile of eluted oil quantity versus pressure is used to estimate the MMP. While this method is generally regarded as accurate, it tends to be time-consuming and costly [3]. Another, increasingly popular method is using the rising bubble apparatus (RBA), which estimates the MMP based on the visual observation of injection gas bubbles rising through a stagnant column of oil at varying pressure levels [4]. While this method is claimed to be faster and less costly than using the slim tube apparatus, it has the major drawback of involving the operator's subjectivity in interpreting the geometry of the bubbles.

Estimation of MMP using a computational approach has been proposed as an alternative to the conventional laboratory measurement methods that offers lower costs and a higher flexibility to changes in fluid composition. The various computational methods proposed in the literature can be divided into three major approaches, namely 1-dimensional analytical computation, 1-dimensional slim tube approximation, and single or multiple mixing-cell methods [5].

The 1-dimensional analytical computation approach is based on the analytical solution of flow equations as described by Orr [6]. Utilizing this analytical approach, Orr, et al. [7] and Johns, et al. [8] have identified three key tie lines in systems containing more than 3 components, namely initial, injection and crossover tie lines. These authors further defined MMP as the pressure at which 
any of these key tie lines becomes critical. For a system containing a number of components $\left(\mathrm{n}_{\mathrm{c}}\right)$ Johns and Orr [9] concluded that the number of key tie lines associated with the miscibility development is $\mathrm{n}_{\mathrm{c}}-1$. These key tie lines consist of an injection tie line intersecting the injection gas composition, an initial tie line intersecting the crude oil composition, and $\mathrm{n}_{\mathrm{c}}-3$ crossover tie lines connecting the injection and initial tie lines. In 1-dimensional slim tube approximation, oil recovery obtained by slim tube experiments is estimated by fine-grid compositional computation. In addition to consuming considerable computing time, such a method is prone to numerical dispersion [10].

In the mixing cell approach, the gas and oil are mixed in repeated contacts, either in a single or a series of perfectly mixed cells [11]. Equilibrium vaporliquid compositions resulting from these contacts are determined by flash calculations, and are used to determine the key tie lines. Jaubert, et al. [12] described the multiple-mixing cell (MMC) model as a series of equilibrium cells in which vapor-liquid phase equilibration occurs via flashing, as presented in Figure 1. The authors proposed that MMP is strictly a thermodynamic property that is not influenced by fluid-flow variables such as relative permeability, capillary pressure, and interfacial tension. Among the various MMP computation methods, the MMC model is particularly attractive due to its simplicity and computational robustness. By describing the gas-oil contact as a series of perfectly mixed cells, the key problem in MMP computation is reduced to the selection of the appropriate thermodynamic equation of state for computing the vapor-liquid equilibrium of the MGF-EOR system.

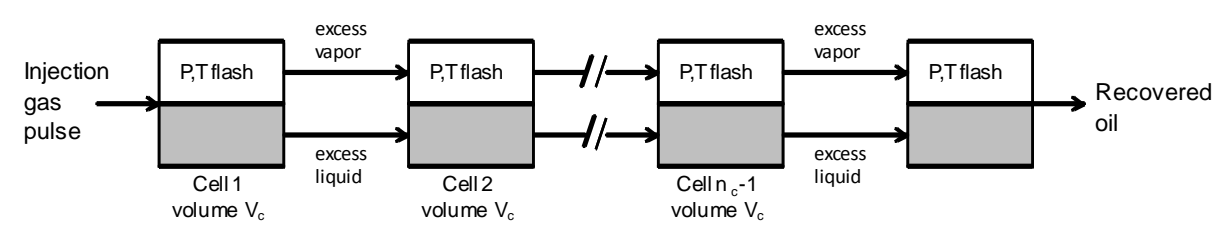

Figure 1 Schematic description of the multiple mixing-cell (MMC) model.

This study represents a preliminary evaluation of the technical feasibility of using flare gas as an injection gas in the MGF-EOR process. Essentially, this evaluation involves the comparison of the MMP values for flare gas injection with those for the conventional $\mathrm{CO}_{2}$ injection process.

\section{$2 \quad$ Methodology}

As a preliminary investigation, the oil and flare gas compositions are represented by model mixtures containing minimum numbers of components. The use of systems with measured MMP values in the available literature is 
preferred. Based on these criteria, a binary system containing $n-\mathrm{C}_{5} \mathrm{H}_{12}$ and n$\mathrm{C}_{16} \mathrm{H}_{34}$ at a molar ratio of $43 \%: 57 \%$ was selected as the model oil. Two gas injection cases for this binary oil are considered in this work, namely: (1) injection by pure $\mathrm{CO}_{2}$, which constitutes a ternary system, and (2) injection by a binary model flare gas consisting of $\mathrm{CH}_{4}$ and $\mathrm{C}_{2} \mathrm{H}_{6}$ at a molar ratio of $91 \%$ :9\%, which constitutes a quaternary system. The $\mathrm{CO}_{2}$ miscible flooding of this model oil has been described by Mihcakan and Poettman [4]. The methane-ethane ratio in the model flare gas was obtained from the normalization of the average flare gas composition in Indonesia described by Crosetti and Fuller [2]. In accordance with the laboratory estimation of MMP described by Mihcakan and Poettman [4], the temperature for the MMP computations was set at $323.15 \mathrm{~K}$ for all runs.

Two families of thermodynamic equations of state were considered in this study, namely cubic and analytical equations of state. The cubic equation of state is represented by the widely used Peng-Robinson model. The analytical equation of state is represented by two forms of the statistical associating fluid theory (SAFT) method. The latter method is derived from Wertheim's perturbation theory, in which the Helmholtz free energy of a real fluid is expressed as the sum of a reference fluid (or ideal fluid) contribution and a residual energy contribution [13]. The two forms of SAFT selected for this study are the SAFT-HR model developed by Huang and Radosz in 1990 [14], and the PC-SAFT model developed by Gross and Sadowski in 2001 [15]. SAFT-HR is regarded as the first successful engineering version of SAFT. The reference fluid in the SAFT-HR model is an ensemble of hard spheres. The residual free energy contribution is described as the sum of: (1) repulsive interactions between the hard spheres, (2) energy change due to the formation of molecules, described as chains of hard spheres, (3) non-specific repulsive forces described as dispersion, (4) specific associative forces between the molecules (or between the chains of hard spheres), representing such forces as polar molecules interactions, hydrogen bonding, etc. The PC-SAFT, or perturbed chain SAFT model, is one of the most widely used fundamental modifications of the original SAFT model. The PC-SAFT model employs an ensemble of hard chains in lieu of hard spheres as the reference fluid. While the mathematical procedures entailed in the PC-SAFT model are fundamentally equivalent to those in the SAFT-HR model, the structural parameters required to describe molecules and intermolecular interactions are obviously different, owing to the fundamentally different description of the reference fluid.

The multiple mixing-cell model originally described by Metcalfe, et al. [11] and modified by Jaubert, et al. [12] was used as the core simulation method for MMP estimation. The schematic diagram of this model is presented in Figure 1. As outlined previously, the MMC computation method involves a series of gas 
and oil mixtures, vapor-liquid equilibrium composition determination via $\mathrm{P}, \mathrm{T}$ flash calculations, and partitioning and transfer of the equilibrated fluids to the next mixing cell. After each P,T-calculation in a particular cell is completed, the partitioning rules described by Jaubert, et al. [12] are applied:

1. If the cell contains only vapor or liquid, then transfer the fluid in excess of the cell volume to the next cell.

2. If the cell contains both vapor and liquid phases, the vapor phase takes priority over the fluid transfer:

- transfer the vapor in excess of the cell volume to the next cell

- if the entire vapor phase has been moved and the volume of the remaining liquid is still larger than the cell volume, then transfer the excess liquid phase to the next cell.

The MMC computation in this study was undertaken using a Fortran-based package described in an earlier work [16]. Prior to the calculations, the user defines the fluid composition and relative quantities (with the gas to oil molar ratio or GOR), pressure and temperature of the system, and pure and binary interaction parameters of the system components.

Binary interaction parameters $\mathrm{k}_{\mathrm{ij}}$ for the Peng-Robinson equation of state were obtained from the literature [17]. The values for SAFT-HR and PC-SAFT were obtained by trial-and-error fitting of VLE composition data of each binary pair. Table 1 provides a list of the binary interaction parameters employed in this study.

Table 1 Binary interaction parameters $\left(\mathrm{k}_{\mathrm{ij}}\right)$ used in this study.

\begin{tabular}{lccc}
\hline \multicolumn{1}{c}{ Binary pair } & \multicolumn{3}{c}{ Binary } \\
& Peng-Robinson & SAFT-HR & PC-SAFT \\
\hline $\mathrm{CH}_{4}-\mathrm{nC}_{5} \mathrm{H}_{12}$ & 0.0236 & 0.077 & 0.024 \\
$\mathrm{CH}_{4}-\mathrm{nC}_{16} \mathrm{H}_{34}$ & 0.0451 & 0.150 & 0.050 \\
$\mathrm{C}_{2} \mathrm{H}_{6}-\mathrm{nC}_{5} \mathrm{H}_{12}$ & 0.0078 & 0.015 & 0.010 \\
$\mathrm{C}_{2} \mathrm{H}_{6}-\mathrm{nC}_{16} \mathrm{H}_{34}$ & 0.042 & 0.051 & 0.025 \\
$\mathrm{CO}_{2}-\mathrm{nC}_{5} \mathrm{H}_{12}$ & 0.140 & 0.130 & 0.124 \\
$\mathrm{CO}_{2}-\mathrm{nC}_{16} \mathrm{H}_{34}$ & 0.110 & 0.146 & 0.130 \\
\hline
\end{tabular}

After the binary $\mathrm{k}_{\mathrm{ij}}$ parameters had been defined for all binary pairs, two steps followed:

1. binary VLE calculations to select the SAFT equation that produces the highest accuracy.

2. MMC computation to estimate the MMP values for the cases of $\mathrm{CO}_{2}$ injection and flare gas injection, using the Peng-Robinson and the SAFT equation of states selected in the previous step. 
To estimate the MMP value from the multiple mixing-cell calculation requires the replacement of Jaubert's original method of computing the oil recovery at gas injection of 1.2 times the pore volume by a simplified constant tie length zone identification as described by Ahmadi and Johns [18]. In this approach, key tie lines are identified as constant line zones in the tie line vs. cell number results. As the pressure is increased, key tie line lenghts are decreased, with the length of the critical tie line decreasing faster with pressure compared to the other key tie lines [18]. When the length of the critical tie line is sufficiently close to zero, the computation is terminated, and the tie line length versus pressure curve is extrapolated to zero length to obtain the MMP.

\section{$3 \quad$ Results and Discussion}

\subsection{Binary VLE Calculations}

Figures 2 through 7 present the binary VLE calculation results obtained using the Peng-Robinson, SAFT-HR, and PC-SAFT equations of state. The results are presented as pressures vs. liquid and vapor composition. References for the VLE data are included in Table 2.

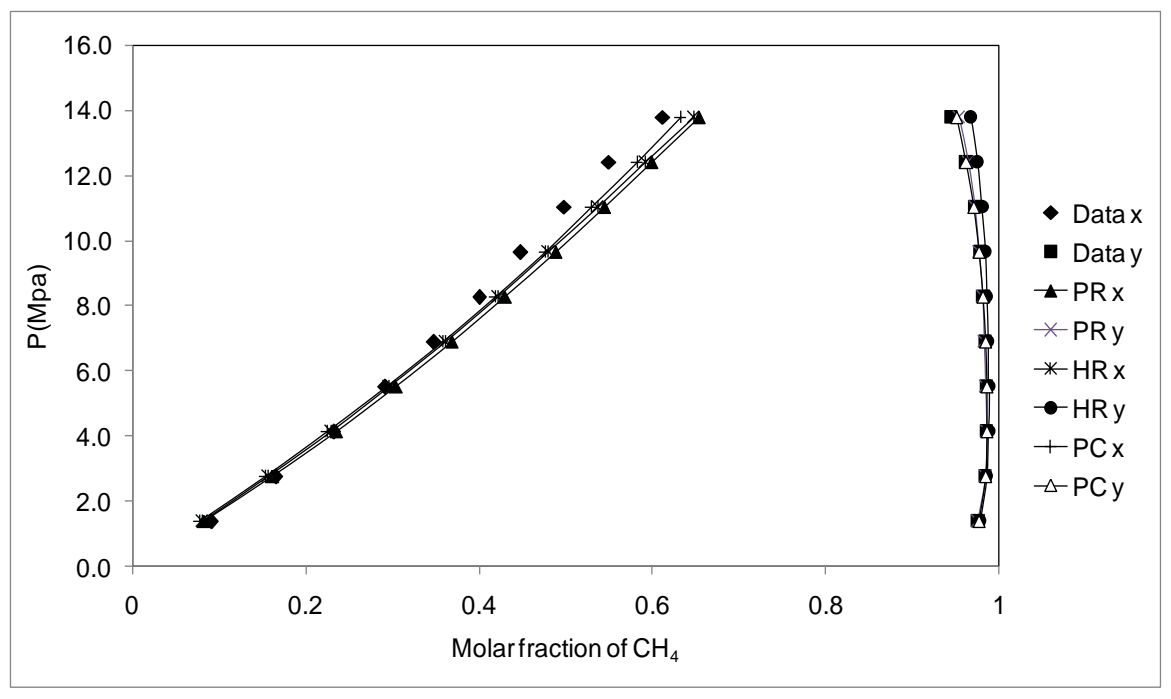

Figure 2 Binary VLE calculation results for the $\mathrm{CH}_{4}-\mathrm{nC}_{5} \mathrm{H}_{12}$ pair at $273.16 \mathrm{~K}$. 


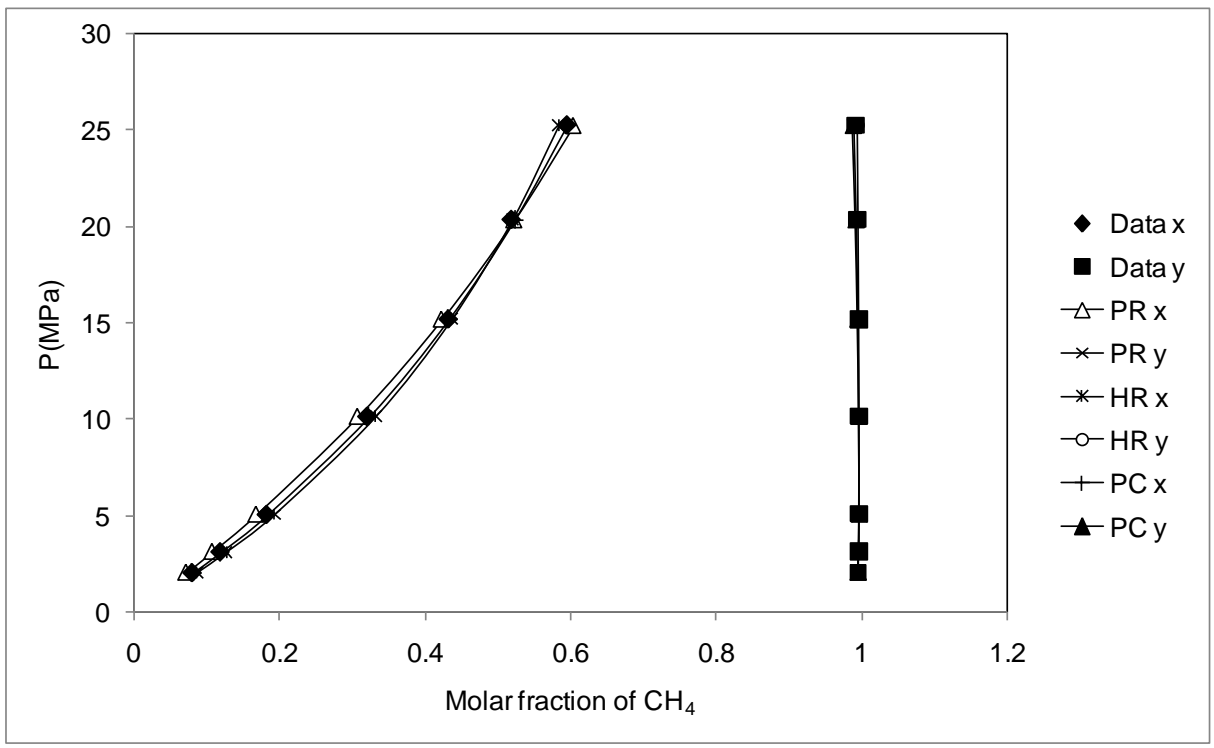

Figure 3 Binary VLE calculation results for the $\mathrm{CH}_{4}-\mathrm{nC}_{16} \mathrm{H}_{34}$ pair at $462.3 \mathrm{~K}$.

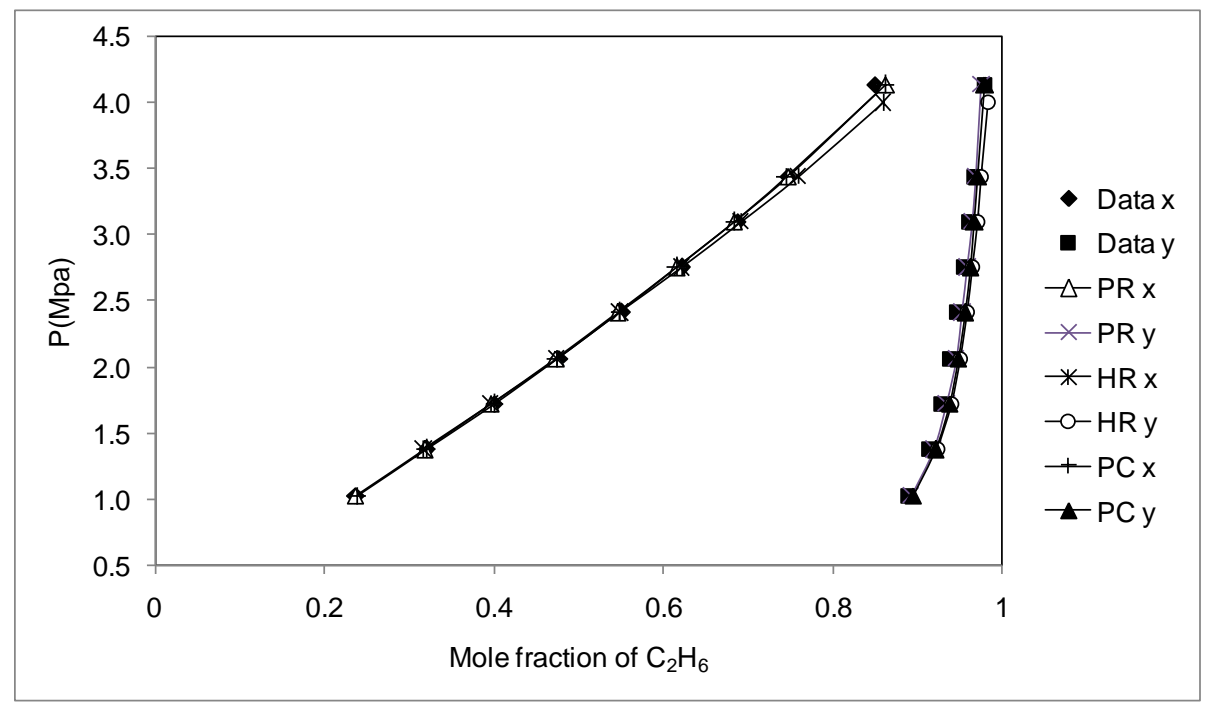

Figure 4 Binary VLE calculation results for $\mathrm{C}_{2} \mathrm{H}_{6}-\mathrm{nC}_{5} \mathrm{H}_{12}$ pair at $310.78 \mathrm{~K}$. 


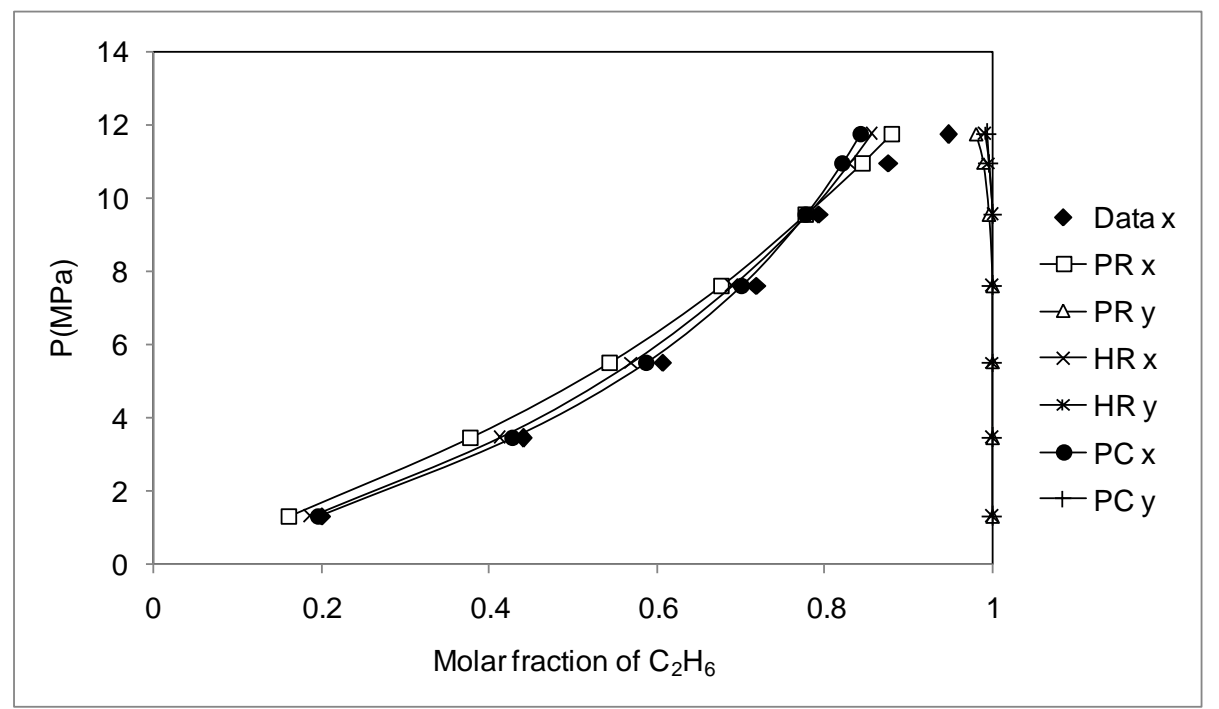

Figure 5 Binary VLE calculation results for $\mathrm{C}_{2} \mathrm{H}_{6}-\mathrm{nC}_{16} \mathrm{H}_{34}$ pair at $363.15 \mathrm{~K}$.

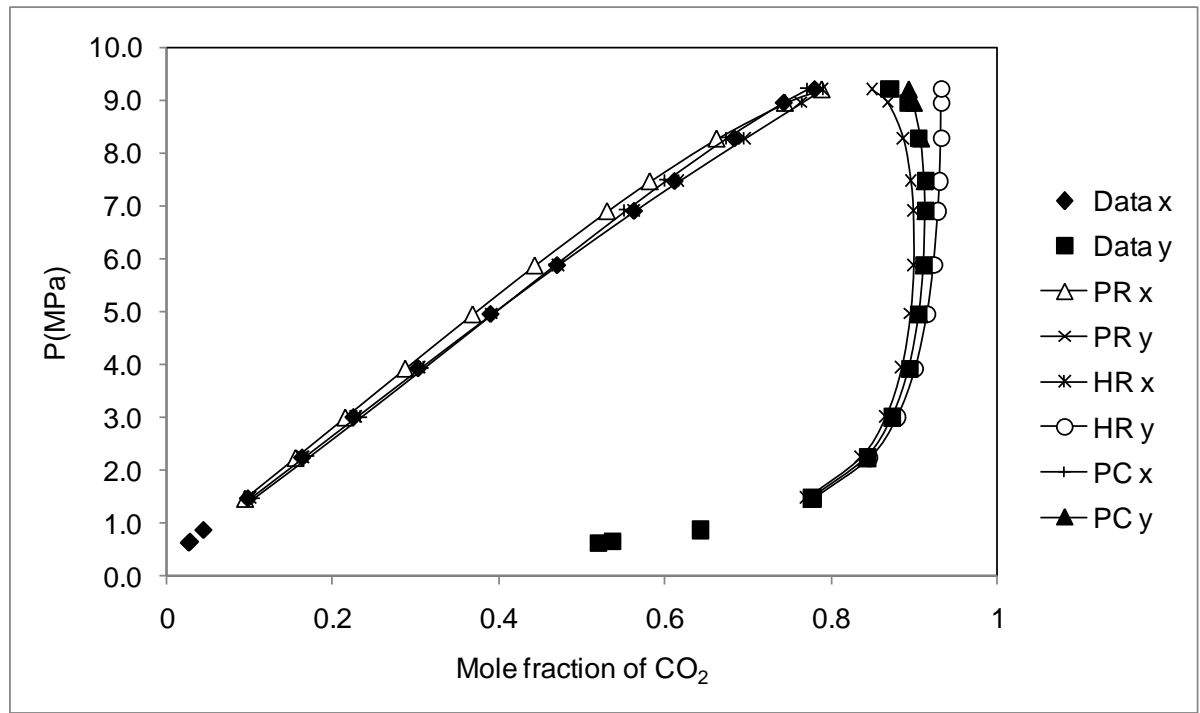

Figure 6 Binary VLE calculation results for $\mathrm{CO}_{2}-\mathrm{nC}_{5} \mathrm{H}_{12}$ pair at $344.15 \mathrm{~K}$. 


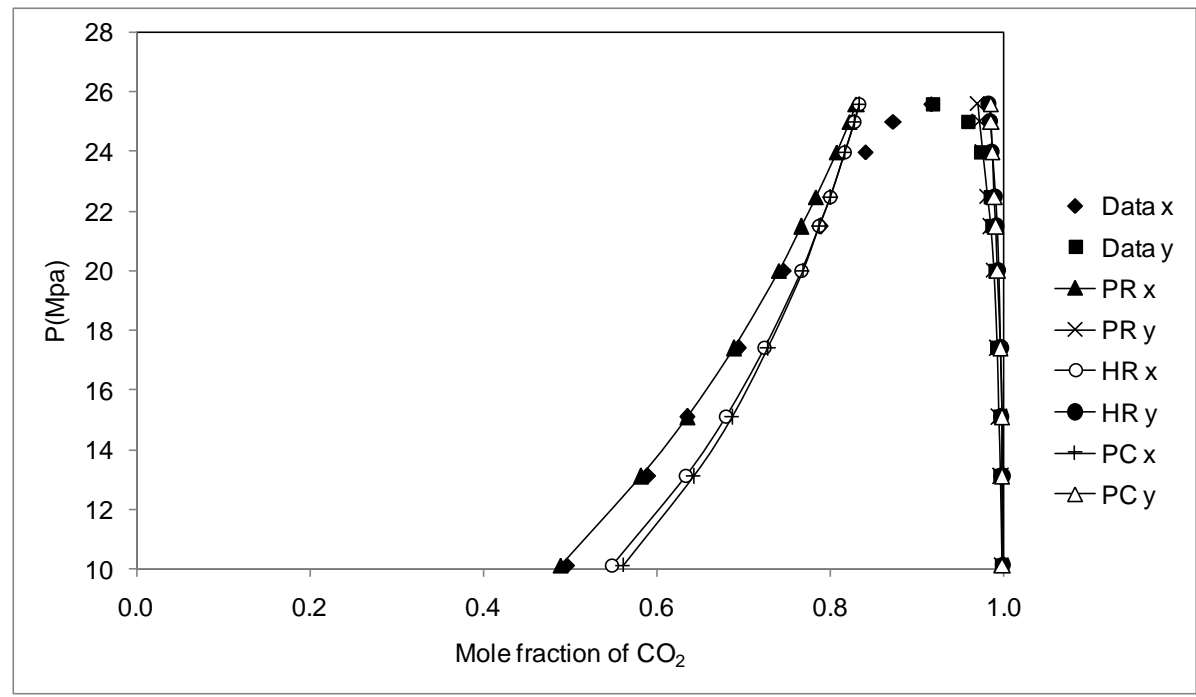

Figure 7 Binary VLE calculation results for $\mathrm{CO}_{2}-\mathrm{nC}_{16} \mathrm{H}_{34}$ pair at $393.2 \mathrm{~K}$.

Table 2 Accuracy of the Peng-Robinson, SAFT-HR, and PC-SAFT equations of state in binary VLE modeling.

\begin{tabular}{cccccc}
\hline \multirow{2}{*}{ System } & \multirow{3}{*}{$\mathbf{T}, \mathbf{K}$} & \multicolumn{3}{c}{$\begin{array}{c}\text { Average absolute deviation (AAD) } \\
\text { of compositions }\end{array}$} & \multirow{2}{*}{ Reference for data } \\
\cline { 3 - 5 } & & $\mathbf{P - R}$ & SAFT-HR & PC-SAFT & \\
\hline $\mathrm{CH}_{4}-\mathrm{nC}_{5} \mathrm{H}_{12}$ & 273.16 & 0.0134 & 0.0138 & 0.0090 & {$[19]$} \\
$\mathrm{CH}_{4}-\mathrm{nC}_{16} \mathrm{H}_{34}$ & 462.3 & 0.0058 & 0.0039 & 0.0011 & {$[20]$} \\
$\mathrm{C}_{2} \mathrm{H}_{6}-\mathrm{nC}_{5} \mathrm{H}_{12}$ & 310.78 & 0.0043 & 0.0075 & 0.0052 & {$[21]$} \\
$\mathrm{C}_{2} \mathrm{H}_{6}-\mathrm{nC}_{16} \mathrm{H}_{34}$ & 363.15 & 0.0456 & 0.0366 & 0.0328 & {$[22]$} \\
$\mathrm{CO}_{2}-\mathrm{nC}_{5} \mathrm{H}_{12}$ & 344.15 & 0.0143 & 0.0121 & 0.0052 & {$[23]$} \\
$\mathrm{CO}_{2}-\mathrm{nC}_{16} \mathrm{H}_{34}$ & 393.2 & 0.0157 & 0.0234 & 0.0250 & {$[24]$} \\
\multicolumn{2}{l}{ Overall average } & 0.0165 & 0.0162 & 0.0130 & \\
\hline
\end{tabular}

In general, Figures 2 through 7 indicate that all three equations of state provide a very good fit with the vapor-phase composition data for systems not containing $\mathrm{CO}_{2}$. This is especially true at low to intermediate pressures. Figures 5 and 6 suggest that the Peng-Robinson model tends to be more accurate near the critical point. For the $\mathrm{CO}_{2}-\mathrm{nC}_{16} \mathrm{H}_{34}$ system, which seems to exhibit the largest dissimilarity in terms of polarity and molecular geometry of all pairs in Table 2, all three equations of state indicate poor agreement in the vicinity of the critical point. This behavior is not surprising, since these equations of state are essentially based on the mean-field theory, which involves the evaluation of exponentially-behaved quantities near the critical point, which makes convergence of the computation difficult [25]. The Peng-Robinson model 
produces the best fit with the liquid-phase composition data at low to intermediate pressure levels.

The absolute errors of the binary VLE calculation results compiled in Table 2 suggest that the overall accuracy of the Peng-Robinson model is comparable to that of the SAFT-HR model for binary systems relevant to this study. Of the two SAFT models, PC-SAFT exhibits the highest accuracy. Therefore, the Peng-Robinson and PC-SAFT models were selected for the subsequent work of computing the MMP values of $\mathrm{CO}_{2}$ and flare gas injection systems.

\subsection{MMP Estimation}

In the MMC computation, the simulation package records vapor-liquid equilibrium compositions in each mixing cell if the overall fluid composition of the cell lies in the two-phase region of the system. The vapor-liquid equilibrium compositions are then used to calculate the tie line length of each mixing cell, resulting in reduced data set in the form of tie line length versus cell number curves.

The predicted phase behavior of the ternary $\mathrm{CO}_{2}-\mathrm{C}_{5} \mathrm{H}_{12}-\mathrm{C}_{16} \mathrm{H}_{34}$ system representing the $\mathrm{CO}_{2}$ injection case is presented in Figure 8. This figure plots the two-phase boundary predicted by the Peng-Robinson and the PC-SAFT equations of state at $10.34 \mathrm{MPa}$ and $323.15 \mathrm{~K}$. Data points measured by Mihcakan and Poettman [4] are included in the ternary diagram.

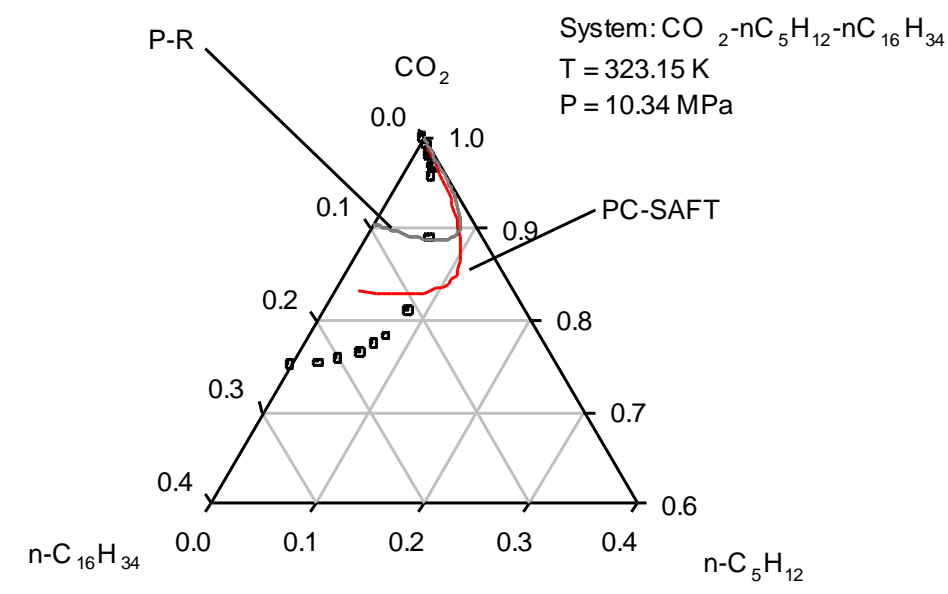

Figure 8 Phase behavior of $\mathrm{CO}_{2}-\mathrm{nC}_{5} \mathrm{H}_{12}-\mathrm{nC}_{16} \mathrm{H}_{34}$ ternary system predicted by Peng-Robinson (P-R) and PC-SAFT equations of state at $323.15 \mathrm{~K}$ and 103.4 bar. 
Figure 8 indicates that both equations of state are generally not capable of accurately predicting the heavy (or liquid) phase composition. The PengRobinson equation of state predicts a narrower phase envelope compared to PCSAFT. As will be evident from the MMP estimation, this difference manifests itself in a lower MMP predicted by the Peng-Robinson equation of state.

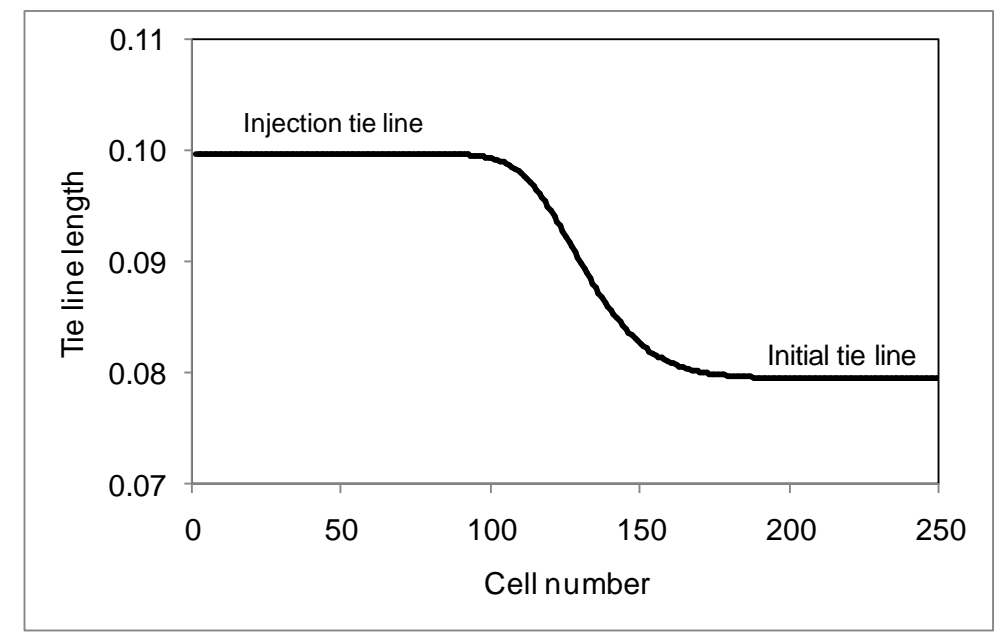

Figure 9 Example of $\mathrm{MMC}$ computation raw data for $\mathrm{CO}_{2}$ injection of $\mathrm{nC}_{5} \mathrm{H}_{12}$ $\mathrm{nC}_{16} \mathrm{H}_{34}$ (molar ratio 43\%:57\%) model oil at $323.15 \mathrm{~K}$ and $9.4 \mathrm{MPa}$, using PCSAFT equation of state.

Figure 9 provides an example of tie line length vs. cell number data for the $\mathrm{CO}_{2}$ injection case, as calculated using the PC-SAFT equation of state. Since this is a ternary system $\left(\mathrm{n}_{\mathrm{c}}=3\right)$, two types of key tie lines are observed, i.e. injection and initial tie lines. These key tie lines are identified as constant-length zones in Figure 8 . The shorter length of the initial tie line suggests that this particular tie line will become critical (i.e. its length approaches zero) at MMP. The role of the initial tie line as the critical one suggests that the $\mathrm{CO}_{2}$ miscibility occurs through the vaporizing gas drive mechanism (VGDM), in which the dry injection gas vaporizes the intermediate hydrocarbons from the oil [26].

When the binary model flare gas is used as the injection gas, the gas-oil system becomes a quaternary system. Thus, as indicated in Figure 10, three types of key tie lines are identified. This figure provides an example of the raw data obtained by MMC computation for the flare gas injection case. This particular example was obtained from the computation at $323.15 \mathrm{~K}$ and $36.0 \mathrm{MPa}$. The crossover tie line is the critical tie line in this case. The criticality of the crossover tie line indicates that the mechanism of oil displacement by the 
injection gas is shifted from VGDM in the $\mathrm{CO}_{2}$ injection case to a combined vaporizing/condensing gas drive in the flare gas injection case [27].

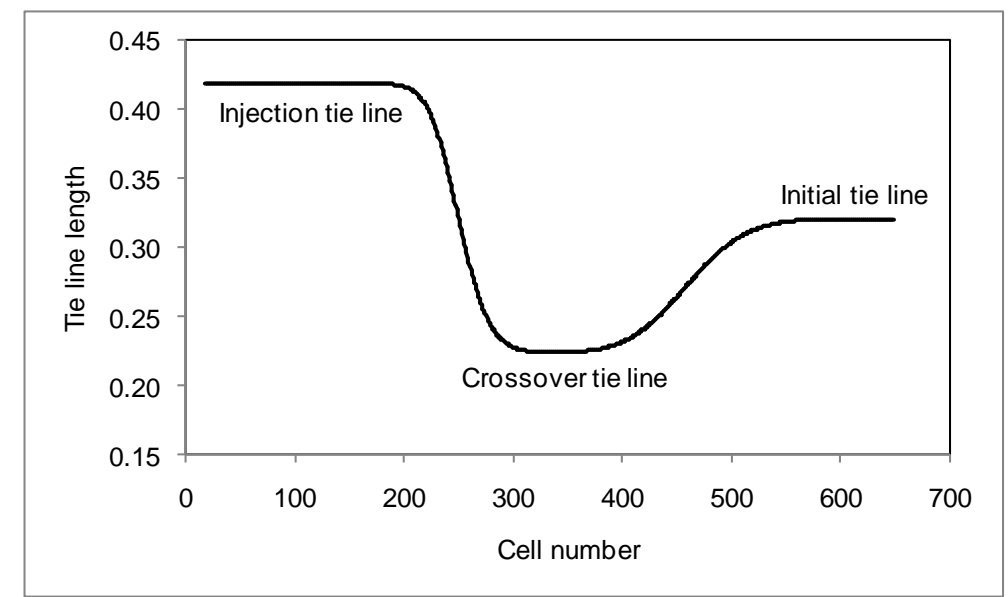

Figure 10 Example of MMC computation raw data for flare gas $\left(91 \% \mathrm{CH}_{4}: 9 \%\right.$ $\mathrm{C}_{2} \mathrm{H}_{6}$ ) injection of $\mathrm{nC}_{5} \mathrm{H}_{12}-\mathrm{nC}_{16} \mathrm{H}_{34}$ (molar ratio $43 \%: 57 \%$ ) model oil at $323.15 \mathrm{~K}$ and 36.0 MPa, using PC-SAFT equation of state.

As the system pressure is increased, the length of all key tie lines decreases. Figure 11 describes the impact of pressure on key tie line lengths for the $\mathrm{CO}_{2}$ injection case. By extrapolating the tie line length of the initial tie line using a cubic polynomial curve, the MMP values predicted by using the Peng-Robinson and the PC-SAFT equations of state are 9.78 and $10.20 \mathrm{MPa}$, respectively. Compared to the $10.55 \mathrm{MPa}$ MMP value measured by the slim tube method reported by Yang, et al. [28], PC-SAFT provides a better estimate than the Peng-Robinson model. While the accuracy of both equations of state is quite satisfactory in this case, they predict substantially different tie line lengths at pressures above $9.4 \mathrm{MPa}$, indicating that the two-phase envelopes generated by these equations are also substantially different at higher pressure-levels.

The MMP estimation for the flare gas injection case is described in Figure 12. Compared to the $\mathrm{CO}_{2}$ injection case, the discrepancy between the results obtained using the Peng-Robinson model and those using PC-SAFT are much more substantial, even at pressures much lower than the critical point. Comparing the behavior of the Peng-Robinson and the PC-SAFT equations of state in the critical region, it is likely that the results using the Peng-Robinson model are more accurate. While the current study is preliminary in nature, and therefore does not place a heavy emphasis on the optimization of binary interaction parameters of the equations of state, this large discrepancy may signal that there is room for substantially better parameter optimization, 
especially for $\mathrm{CO}_{2}$-containing pairs for PC-SAFT, to improve the description of VLE behavior in the critical region.

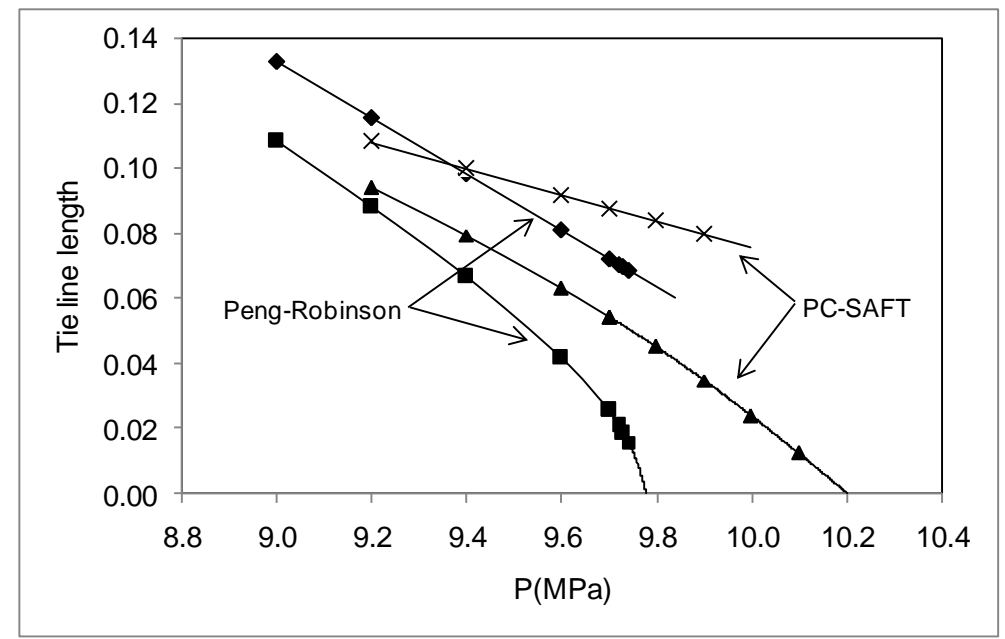

Figure 11 Key tie line lengths as functions of pressure for $\mathrm{CO}_{2}$ injection of $\mathrm{nC}_{5} \mathrm{H}_{12}-\mathrm{nC}_{16} \mathrm{H}_{34}$ (molar ratio 43\%:57\%) model oil at $323.15 \mathrm{~K}(\bullet=$ injection tie line using Peng-Robinson model, = = initial tie line using Peng-Robinson model, $\times=$ injection tie line using PC-SAFT model, $\boldsymbol{\Delta}=$ initial tie line using PC-SAFT model).

The MMP values predicted for the flare gas injection case using the PengRobinson and the PC-SAFT equations of state are 35.7 and 46.0 MPa, respectively. These values are approximately 3.6-4.5 times the values obtained using $\mathrm{CO}_{2}$ as the injection gas. This extremely large increase in MMP is due to the lower solubility of methane and ethane in crude oil compared to the solubility of $\mathrm{CO}_{2}$. This behavior has been observed in miscible gas flooding studies of light and heavy crude oils by DeRuiter, et al. [29], Teletzke, et al., [3], and Bon and Sarma [30]. All of these authors observe through both experimental and simulation studies that $\mathrm{CO}_{2}$ produces the lowest MMP of the light gases employed for miscible and immiscible gas flooding. These gases include $\mathrm{CO}_{2}, \mathrm{~N}_{2}$, natural gas, associated gas from oilfields, flue gas, and $\mathrm{H}_{2} \mathrm{~S}$ containing acid gases.

The large pressure increment required for creating multiple-contact miscibility in flare gas injection poses several substantial challenges for the further development of the MGF-EOR process. In addition to increasing the investment costs and operating expenses, such high miscibility pressure requirements may compromise the integrity of the rock formation structure of the reservoir. These 
drawbacks should be weighed against the potential benefit of GHG emission reduction offered by the miscible flare gas injection process. Explorative studies on the effect of mixing flare gas with other components shall be undertaken. These studies will include the enrichment of the flare gas with intermediate components (in the propane-pentane range), and the combination of $\mathrm{CO}_{2}$ and flare gas, in which the $\mathrm{CO}_{2}$ may be produced by partial combustion of the flare gas.

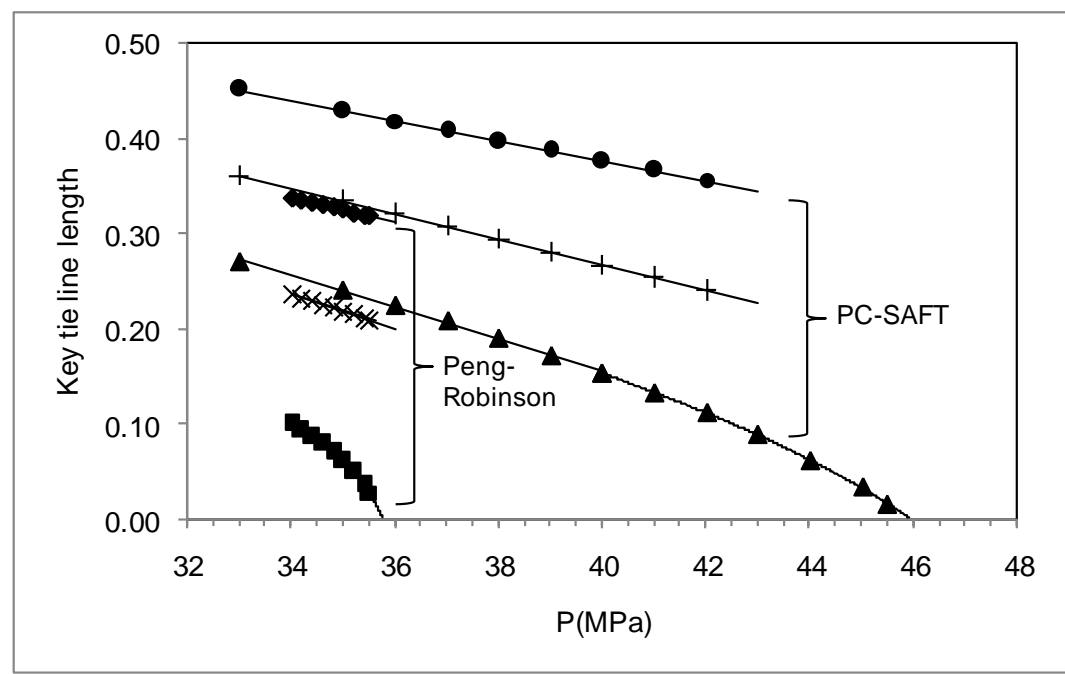

Figure 12 Key tie line lengths as functions of pressure for flare gas $\left(91 \% \mathrm{CH}_{4}\right.$ $9 \% \mathrm{C}_{2} \mathrm{H}_{6}$ ) injection of $\mathrm{nC}_{5} \mathrm{H}_{12}-\mathrm{nC}_{16} \mathrm{H}_{34}$ (molar ratio $43 \%: 57 \%$ ) model oil at 323.15 K ( $\diamond=$ injection tie line using Peng-Robinson model, $\mathbf{\square}=$ crossover tie line using Peng-Robinson model, $\times=$ initial tie line using Peng-Robinson model, $\mathbf{O}=$ injection tie line using PC-SAFT model, $\mathbf{\Delta}=$ crossover tie line using PC-SAFT model, + = initial tie line using PC-SAFT model).

\section{Conclusions}

In the prediction of binary vapor-liquid equilibrium composition data containing $\mathrm{CO}_{2}, \mathrm{nC}_{5} \mathrm{H}_{12}$, and $\mathrm{nC}_{16} \mathrm{H}_{34}$, Peng-Robinson and PC-SAFT equations of state produce good accuracy at low to intermediate pressure levels. In the vicinity of the critical point, the Peng-Robinson model provides a higher overall accuracy. Computation of miscible $\mathrm{CO}_{2}$ flooding of the model $\mathrm{nC}_{5} \mathrm{H}_{12}-\mathrm{nC}_{16} \mathrm{H}_{34}$ oil at $323.15 \mathrm{~K}$ using the multiple mixing-cells model produces MMP values that are close to the published laboratory measurement value of $10.55 \mathrm{MPa}$. The use of a $91 \% \mathrm{CH}_{4}-9 \% \mathrm{C}_{2} \mathrm{H}_{6}$ model flare gas as the injection gas increases the MMP by 3.6-4.5 times compared to $\mathrm{CO}_{2}$ injection, raising concerns about high 
compression costs and integrity of the reservoir structure if flare gas is used for miscible gas flooding.

\section{Acknowledgments}

This study was funded by the ITB Research Group Research and Innovation Grant 2011 (Riset dan Inovasi Kelompok Keahlian ITB 2011). The authors wish to thank the ITB Institute for Research and Community Empowerment (LPPM-ITB) for administering the research grant.

\section{References}

[1] Indriani, G., Gas Flaring Reduction in the Indonesian Oil and Gas Sector: Technical and Economic Potential of Clean Development Mechanism (CDM) Projects, Hamburg Institute of International Economics, Hamburg, Germany, pp. 46-53, 2005.

[2] Crosetti, M. \& Fuller, D., Indonesia Associated Gas Survey - Screening and Economic Analysis Report, The World Bank/GGFR, Jakarta, Indonesia, pp. 2.4-2.6, 4.4, 2006.

[3] Teletzke, G.F., Patel, P.D. \& Chen, A.L., Methodology for Miscible Gas Injection EOR Screening, SPE Paper No. 97650, SPE International Improved Oil Recovery Conference, Kuala Lumpur, Malaysia, 5-6 December 2005, pp. 1-11, 2005.

[4] Mihcakan, M.J. \& Poettmann, F.H., Minimum Miscibility Pressure, Rising Bubble Apparatus and Phase Behavior, SPE 27815, 1994 SPE/DOE Symposium on Improved Oil Recovery, Tulsa, Oklahoma, USA, 17-20 April 1994, pp. 361-369, 1994.

[5] Ahmadi, K. \& Johns, R.T., Multiple Mixing-Cell Method for MMP Calculations, SPE 116823, 2008 SPE Annual Technical Conference and Exhibition, 21-24 September 2008, Denver, Colorado, USA, pp. 1-10, 2008.

[6] Orr, F.M., Theory of Gas Injection Processes, Stanford University, Menlo Park, California, USA, pp. 5-15, 2005.

[7] Orr, F.M., Johns, R.T. \& Dindoruk, B., Development of Miscibility in Four-Component $\mathrm{CO}_{2}$ Floods, SPE Reservoir Engineering Journal, 8(2), pp. 135-142, 1993.

[8] Johns, R.T., Dindoruk, B. \& Orr, F.M., Analytical Theory of Combined Condensing / Vaporizing Gas Drive, SPE Advanced Technology Series, 1(2), pp. 7-16, 1993.

[9] Johns, R.T. \& Orr, F.M., Miscible Gas Displacement of Multicomponent Oils, SPE Journal, 1(1), pp. 39-50, 1996.

[10] Johns, R.T., Sah, P. \& Solano, R., Effect of Dispersion on Local Displacement Efficiency for Multicomponent Enriched-Gas Floods above 
the Minimum Miscibility Enrichment, SPE Reservoir Engineering, 5(1), pp. 4-10, 2002.

[11] Metcalfe, R.S., Fussell, D.D. \& Shelton, J.L., A Multicell Equilibrium Separation Model for the Study of Multiple Contact Miscibility in RichGas Drives, SPE Journal, 13(3), pp. 147-155, 1973.

[12] Jaubert, J.N., Wolff, L., Neau, E. \& Avaullee, L., A Very Simple Multiple Mixing Cell Calculation to Compute the Minimum Miscibility Pressure Whatever the Displacement Mechanism, Industrial and Engineering Chemistry Research, 37(12), pp. 4854-4859, 1998.

[13] Chapman, W.G., Gubbins, K.E., Jackson, G. \& Radosz, M., SAFT: Equation-of-State Solution Model for Associating Fluids, Fluid Phase Equilibria, 52, pp. 31-38, 1989.

[14] Huang, S.H. \& Radosz, M., Equation of State for Small, Large, Polydisperse, and Associating Molecules, Industrial and Engineering Chemistry Research, 29, pp. 2284-2294, 1990.

[15] Gross, J. \& Sadowski, G., Perturbed-Chain SAFT: An Equation of State Based on a Perturbation Theory for Chain Molecules, Industrial and Engineering Chemistry Research, 40(4), pp. 1244-1260, 2001.

[16] Samadhi, T.W., Adidharma, H. \& Tan, S.P., Purely Predictive Application of Statistical Associating Fluid Theory for Enhanced Oil Recovery by Miscible Gas Flooding, Proceedings of the 2009 Regional Symposium on Chemical Engineering, Santo Tomas University, Manila, Philippines, December 2009.

[17] Danesh, A., PVT and Phase Behavior of Petroleum Reservoir Fluids, Elsevier Science BV, Amsterdam, Netherlands, pp. 354-360, 1998.

[18] Ahmadi, K. \& Johns, R.T., Multiple Mixing-Cell Model for MMP Determination, SPE Journal, 16(4), pp. 733-742, 2011.

[19] Chu, T.C., Chen, R.J.J., Chappelear, P.S. \& Kobayashi, R., Vapor-Liquid Equilibrium of Methane-n-Pentane System at Low Temperatures and High Pressures, Journal of Chemical Engineering Data, 21(1), pp. 41-44, 1976.

[20] Lin, H.M., Sebastian, H.M. \& Chao, K.C., Gas-Liquid Equilibrium in Hydrogen $+n$-Hexadecane and Methane $+n$-Hexadecane at Elevated Temperatures and Pressures, Journal of Chemical and Engineering Data, 25(3), pp. 252-254, 1980.

[21] Reamer, H.H., Sage, B.H. \& Lacey, W.N., Phase Equilibria in Hydrocarbon Systems: Volumetric and Phase Behavior of Ethane- $n$ Pentane System, Journal of Chemical and Engineering Data, 5(1), pp. 4450, 1960.

[22] De Goede, R., Peters, C.J., Van Der Kooi, H.J. \& Lichtenthaler, R.N., Phase Equilibria in Binary Mixtures of Ethane and Hexadecane, Fluid Phase Equilibria, 50(3), pp. 305-314, 1989. 
[23] Besserer, G.J. \& Robinson, D.B., Equilibrium-Phase Properties of nPentane-Carbon Dioxide System, Journal of Chemical and Engineering Data, 18(4), pp. 416-419, 1973.

[24] Spee, M. \& Schneider, G.M., Fluid Phase Equilibrium Studies on Binary and Ternary Mixtures of Carbon Dioxide with Hexadecane, 1Dodecanol, 1,8-Octanediol and Dotriacontane at $393.2 \mathrm{~K}$ and at Pressures up to 100 MPa, Fluid Phase Equilibria, 65, pp. 263-274, 1991.

[25] Kadanoff, L.P., Statistical Physics: Statics, Dynamics and Renormalization, World Scientific, Singapore, pp. 242-244, 2000.

[26] Jaubert, J.N., Arras, L., Neau, E. \& Avaullee, L., Properly Defining the Classical Vaporizing and Condensing Mechanisms when a Gas is Injected into a Crude Oil, Industrial and Engineering Chemistry Research, 37, pp. 4860-4869, 1998.

[27] Johns, R.T., Dindoruk, B. \& Orr, F.M., An Analytical Theory of Combined Condensing/Vaporizing Gas Drives, SPE Advanced Technology Series, 1(2), pp. 7-16, 1993.

[28] Yang, F., Zhao, G.B., Adidharma, H., Towler, B. \& Radosz, M., Effect of Oxygen on Minimum Miscibility Pressure in Carbon Dioxide Flooding, Industrial and Engineering Chemistry Research, 46(4), pp. 1396-1401, 2007.

[29] DeRuiter, R.A., Nash, L.J. \& Singletary, M.S., Solubility and Displacement Behavior of a Viscous Crude with $\mathrm{CO}_{2}$ and Hydrocarbon Gases, SPE Reservoir Engineering, 9(2), pp. 101-106, 1994.

[30] Bon, J. \& Sarma, H.K., Investigation of the Effect of Injection Gas Composition on $\mathrm{CO}_{2}$-Rich Flooding and its Implications in an Onshore Australian Oilfield, Proceedings of the Canadian International Petroleum Conference 2009, Calgary, Canada, 16-18 June 2009. 